\title{
A PARTICIPAÇÃO POPULAR NA CONSTRUÇÃO DA POLÍTICA PÚBLICA SOBRE MUDANÇA CLIMÁTICA: AUDIÊNCIA JUDICIAL PARTICIPATIVA E CONSULTA PÚBLICA
}

\section{POPULAR PARTICIPATION IN CONSTRUCTION OF PUBLIC POLICY ON CLIMATE CHANGE: JUDICIAL HEARING PARTICIPATORY AND PUBLIC CONSULTATION}

\author{
Simone Hegele Bolson ${ }^{1}$ \\ Napoleão Miranda ${ }^{2}$
}

\section{RESUMO:}

Atendendo às diretrizes internacionais, o Brasil adotou uma política pública de combate e prevenção às mudanças climáticas através da lei 12.187/09 (PNMC); tendo sido consagrado, entre outros, o princípio da participação cidadã. Essa lei está sendo implementada aos poucos e, em âmbito estadual, dentre outras unidades federativas, o estado do Rio Grande do Sul promulgou lei com o mesmo objetivo; a lei 13.594/10 (PGMC) albergou as mesmas diretrizes e princípios da PNMC. Contudo, embora a previsão da participação popular nas questões referentes às mudanças climáticas, ela ainda é incipiente, o que acaba se constituindo em obstáculo à construção de uma cidadania ambiental plena, conforme se infere dos dados referentes à consulta pública realizada sobre o Plano Nacional de Adaptação às Mudanças Climáticas (PNA). No plano jurídico-processual, porém, a possibilidade da realização de uma audiência judicial participativa pode se constituir em um dos modos de concretização do princípio da participação cidadã. O método utilizado no presente trabalho é o indutivo, alicerçando-se na análise de dados disponibilizados pela Agência Nacional de Água (ANA) e Ministério do Meio Ambiente (MMA) e obras de referência na área da política pública sobre mudanças climáticas, além de artigos pertinentes ao tema.

PALAVRAS-CHAVE: Participação Popular; Política Pública; Mudanças Climáticas.

\footnotetext{
${ }^{1}$ Doutoranda do Programa de Pós-Graduação em Sociologia e Direito - UFF E-mail: simonehbolson@uft.edu.br

2 Professor-Doutor do Programa de Pós-Graduação em Sociologia e Direito - UFF E-mail: napomiranda@gmail.com
} 


\begin{abstract}
Given the international guidelines, Brazil adopted a public policy to combat and prevent climate change by Law 12.187/ 09 (NPCC); having been established, among others, the principle of citizen participation. This a wis being implemented gradually, and at the state level, among other federal units, the state of Rio Grande do Sul enacted law with the same objective; the Law 13.594/10 (PGMC) adopted the same guidelines and principles of NPCC. However, although the forecast of popular participation in issues related to climate change, it is still incipient, which end sup constituting building a full environmental citizenship, as shown byt he data concerning the public consultation of a National plan for Adaptation to Climate Change. In the legal-procedural level, however, the possibility of carrying out a participatory judicial hearing may constitute one of the ways of implemen ting the principle of citizen participation. The method used in this work is the inductive one, based on the analysis of data provided by the National Water Agency (ANA) and the Ministry of Environment (MMA) and reference works in the area of public policy on climate change as well as articles relevant to the topic.
\end{abstract}

KEY WORDS: Popular Participation; Public Policy; Climate Change.

\title{
INTRODUÇÃO
}

As mudanças climáticas e as implicações socioeconômicas de sua incidência nas mais distintas regiões do Planeta hoje são tema das mais prosaicas conversas; elas ingressaram no discurso jurídico ainda na década de 70 do século passado, mas somente com a divulgação dos relatórios do Painel Intergovernamental sobre Mudanças Climáticas (IPCC), em meados da década de 90, é que definitivamente emergiram das pesquisas científicas como um dos graves problemas da humanidade. As informações e a publicidade em torno da questão foram eficientes, pois conseguiram produzir um gradual interesse pelo tema. Mas tudo isso estaria relegado a mais um dos compartimentos da história da civilização humana se as constantes catástrofes não estivessem atingindo áreas cada vez maiores do globo.

Há uma dimensão global, por evidente, das mudanças climáticas; mas esquece-se que em nível local elas também já vêm atingindo a todos. Temporais, inundações, enchentes, longos períodos de estiagem, tudo isso já existia, contudo não com tanta frequência, nem com tanta intensidade. Isso torna mais perceptível 
que se está sim diante de um novo cenário climático e que o risco de desastres ambientais faz parte do dia a dia de todos.

A importância do estudo e análise do fenômeno do aquecimento global e as mudanças climáticas já foram reconhecidos por organizações transdisciplinares como o Climate Institute, dos Estados Unidos e o Institute Des Hautes Études pour la Science et la Technologie, da França. Partindo-se da ideia de que as mudanças climáticas já estão em andamento, embora as consequências mais nefastas estejam previstas para as próximas décadas, e de que não se pode ficar indiferente diante de um quadro que coloca em risco não só a geração atual, mas principalmente as gerações que virão, reveste-se de fundamental importância o estudo de estratégias jurídico-ambientais no enfrentamento das mudanças climáticas, e que o Direito, a Política e a Ciência têm o dever de trazer à tona.

Sob a perspectiva jurídica, a proteção ambiental insculpida no artigo 225 da Constituição Federal há de ser compreendida em uma dupla funcionalidade: 1) como um direito (dever) fundamental do indivíduo e da coletividade; 2) como um objetivo e tarefa estatal (SARLET, 2010, p.92). Nesse último viés, e conectado com as tendências contemporâneas do Direito Internacional Ambiental, o ordenamento jurídico nacional consagrou os princípios que traduzem a disposição do Brasil em trilhar um caminho de mitigação e prevenção às mudanças climáticas, o que efetivamente o fez com a aprovação da Lei 12.187/2009 (Política Nacional sobre Mudança Climática). O artigo 3ํำ dessa Lei expressa os princípios da precaução, prevenção, do desenvolvimento sustentável, da responsabilidade comum e da participação cidadã (popular).

É a participação popular, ainda ausente ou deficiente, nos grandes temas nacionais, em particular os que tratam dos problemas da degradação ambiental, da exploração desenfreada dos recursos naturais e das alterações climáticas decorrentes do aquecimento global o que originou o presente trabalho. Pretende-se, portanto, visualizá-la no âmbito da legislação das políticas públicas sobre mudança do clima, em nível nacional e estadual, por meio da análise do princípio da participação cidadã, seja 1) na implementação do princípio, quando da defesa neste lócus de um novo instrumento jurídico-processual - a audiência judicial participativa; 
2) na investigação de uma consulta pública realizada pelo Ministério do Meio Ambiente (MMA), quando da realização da mesma no final do ano de 2015 , sobre o Plano Nacional de Adaptação à Mudança Climática (PNA).

Como as mudanças climáticas constituem, por si só, um grande campo de investigação de áreas conexas (as Ciências da Terra e as Ciências do, por exemplo) e mesmo as não conexas (a Meteorologia e o Direito, outro exemplo), a delimitação não foi tarefa fácil neste artigo, contudo se busca contribuir à questão da interação entre cidadania ambiental e as mudanças climáticas, mas mais que isso, descortinam-se novas possibilidades no caminho (v.g. audiência pública participativa), antes desconsideradas, interpretados instrumentos os quais os formuladores e executores da política pública de prevenção e mitigação das mudanças climáticas estão utilizando.

\section{AS MUDANÇAS CLIMÁTICAS E O ESTADO DA ARTE}

Em fins do século XIX, o físico britânico John Tyndall investigou e diagnosticou que os gases que se depreendiam das fábricas da Grã-Bretanha não estariam se dissipando como outrora: era o início do estudo sobre o efeito estufa e o aquecimento global (KOLBERT, 2007, p.40). Contudo, somente na década de 60 do século XX a preocupação com o acúmulo desses gases na atmosfera passou a fazer parte das preocupações da academia. Esse aumento excessivo do dióxido de carbono e de outros gases lançados na atmosfera - denominados gases de efeito estufa (GEEs) - é o resultado da passagem da sociedade industrial para a pósindustrial e do processo de acirramento da crise ambiental na última metade do século XX. Tal passagem teve seu ápice nas décadas de 60-70 do século XX, não obstante a crise do petróleo de 1973, que obrigou à busca de alternativas energéticas a esse combustível fóssil, a produção anual do mesmo não recuou, ao contrário, cresceu (GIDDENS, 2010, pp.60-66).

Sendo assim, as mudanças climáticas e as projeções de sua incidência e efeitos sob uma perspectiva científica decorrem principalmente dos fatores antropogênicos, é dizer, de uma ação antrópica: a atividade humana é a maior 
responsável pelo aumento desmedido da emissão de gases de efeito estufa (GEEs). Ao contrário da opinião de vários "céticos" quanto à fundamental participação dos seres humanos no aquecimento do Planeta Terra, as mudanças climáticas têm causas antropogênicas e, portanto, fazem parte da categoria de riscos transtemporais e globais, aos quais Ulrich Beck fazia referência.

Segundo o $5^{\circ}$ (Quinto) Relatório de Avaliação do IPCC (sigla em inglês para Painel Intergovernamental sobre Mudanças Climáticas) há a estimativa de aquecimento global em uma possível variação entre $2,4^{\circ}$ e $6,4^{\circ} \mathrm{C}$, originando um severo câmbio climático, com maior número de enchentes e secas; frequência de eventos extremos; disseminação de doenças letais, além da elevação dos mares (IPCC, 2014). A partir dessas projeções, institutos e grupos de pesquisas nacionais aplicam os modelos do IPCC à nossa realidade climática, como é o caso do INPE (Instituto Nacional de Pesquisas Espaciais); da Embrapa; do COPPE-UFRJ (Instituto de Pós-Graduação e Pesquisa do Departamento de Ciências da UFRJ) e do Forum Brasileiro sobre Mudanças Climáticas. Os ecossistemas, a biodiversidade, o mundo natural, do qual o ser humano faz parte, se encontram em perigo; as emissões de gases de efeito estufa por causas antrópicas, conforme as últimas declarações do IPCC, estão acelerando a destruição da camada de Ozônio e o aquecimento global é uma realidade.

As mudanças climáticas são problemas ecológico-ambientais de segunda geração (CANOTILHO, 2010, p. 21). Ao lado da utilização da energia nuclear, tais mudanças se caracterizam por integrarem um novo estágio da crise ambiental, aquele em que, embora persistentes ainda os problemas de primeira geração (poluição da água, terra e ar), os efeitos combinados de tais problemas constituem novos problemas, os de uma sociedade de risco em que o aquecimento global ingressou na vida cotidiana.

No âmbito da América do Sul, o Brasil lidera os estudos sobre a incidência das mudanças climáticas no continente. Há vários trabalhos produzidos pelas organizações não governamentais (ONGs como o Instituto Socioambiental, de Brasília) e os órgãos governamentais como o Painel Brasileiro sobre Mudanças Climáticas, ligado ao Ministério do Meio Ambiente e o da Integração Regional. Além 
disso, institutos da Administração Pública indireta, como o INPE, indicam o nome dos cientistas de seus quadros para as pesquisas e análises do IPCC, conforme o próximo item.

\subsection{As mudanças climáticas na América do Sul e as projeções do IPCC}

O Painel Intergovernamental sobre Mudanças Climáticas (IPCC) divulgou em Yokohama, no Japão, no final do mês de março de 2014, as projeções sobre as mudanças climáticas ao redor do mundo, condensadas sob capítulos e que fazem parte do 5ำ Relatório do IPCC, dando subsídios ao Acordo do Clima firmado na COP-21, em Paris, no ano de 2015.

No capítulo 27 do documento, que aborda especificamente sobre as projeções para as Américas do Sul e Central, foi destacada a atual vulnerabilidade hídrica nas zonas semiáridas das duas regiões e nos Andes tropicais. Em razão do câmbio climático, haverá um agravamento na falta de água nessas regiões e, se confirmando as projeções, a segurança hídrica nas mesmas será afetada. De outro lado, também a previsão de inundações, em outras regiões, poderá colocar em risco o abastecimento doméstico e industrial de água, comprometendo, inclusive, a produção de alimentos.

Conforme Marcos Buckeridge, professor do Instituto de Biociências da Universidade de São Paulo e um dos autores do capítulo 27 do relatório, "no fim das contas, os principais impactos das mudanças climáticas previstos para as Américas do Sul e Central estão relacionadas com a água" (BUCKERIDGE, 2014). Quanto às projeções do IPCC e os impactos das mudanças climáticas para o futuro, afirmou José Marengo, pesquisador do INPE (Instituto Nacional de Pesquisas Espaciais) e um dos autores do capítulo 27:

Mesmo com as incertezas, já vemos sinais, por exemplo, nos padrões de seca. Grandes áreas da América e da África já sofrem com a seca, e os modelos indicam que isso pode aumentar no futuro se a concentração de gases de efeito estufa continuar subindo. (MARENGO, 2014). 
Antes mesmo do encontro realizado em Yokohama em 2014, o Painel Brasileiro sobre Mudanças Climáticas (PBMC) já havia produzido um documento de avaliação nacional sobre o impacto das mudanças climáticas em nosso país para a Conferência Rio + 20, no qual, a partir dos dados coletados e modelos estabelecidos internacionalmente, projetou-se para os cincos biomas (Amazônia, Caatinga, Cerrado, Pantanal e Mata Atlântica) a incidência das mudanças do clima e de como tais áreas seriam afetadas pelo aumento da temperatura terrestre, com a diminuição das chuvas em determinadas regiões (PBMC, 2012, p.16).

Nesse mesmo documento, ao final, foi firmado pelos cientistas integrantes do PBMC que, embora a incerteza sobre os cenários das emissões globais dos gases de efeito estufa, em geral "os resultados dos modelos conseguiram capturar muito bem o comportamento do clima presente (século $X X$ ) e, assim, a despeito das incertezas, as projeções das mudanças climáticas futuras ao longo do século XXI são plausíveis" (PBMC, 2012, p. 24).

O divulgado pelo IPCC nos últimos dois anos reforça o que vem sendo divulgado desde o 4ํㅡㄹ Relatório, de 2007, vez que as mudanças climáticas fazem parte de uma nova realidade climática. O que deve ser buscado - nesse momento de constatação científica sobre o câmbio climático - são soluções para o enfrentamento das consequências dos efeitos das mudanças climáticas através da implementação de políticas públicas. Uma das cláusulas que os Estados-Parte firmaram no Acordo de Paris, em dezembro do ano passado, foi justamente o de internalizar o que decidiram em planejamento em conjunto durante a Cúpula do Clima.

\section{POLÍTICAS PÚBLICAS SOBRE MUDANÇAS CLIMÁTICAS}

O direito nacional, na direção apontada pelo direito internacional do meio ambiente, não ficou indiferente às perigosas alterações no clima do planeta e, desde 2009, vem internalizando as diretrizes mundiais sobre o tema. Eventos climáticos de potencial destrutivo incalculável, como alguns que afetaram diretamente o Brasil - o ciclone Catarina em 2004, que devastou área entre o Rio Grande do Sul e Santa 
Catarina; a seca na Amazônia em 2005 e 2010; a tragédia na Serra Fluminense em janeiro de 2011; as chuvas incessantes nas bacias do rio Acre e do rio Iguaçu em 2015; a persistente estiagem em parte dos estados do Nordeste - e que tem intrínseca relação com a emissão antrópica dos gases de efeito estufa e o aquecimento global, infelizmente serão mais constantes e com maior potencialidade danosa.

Ainda que com falhas, a Lei 12.187/09 é uma resposta do Estado brasileiro ao desafio da diminuição da emissão dos gases de efeito estudo (os denominados GEEs), mas principalmente é o surgimento de uma política pública nacional que reconhece, combate e previne o aquecimento global e as consequentes mudanças climáticas através de medidas de mitigação e/ou adaptação. E no âmbito estadual, vários estados brasileiros também já aprovaram leis nos mesmos moldes da Política Nacional sobre Mudança do Clima, como é o caso de São Paulo e da Bahia. No Rio Grande Sul a lei foi promulgada em dezembro de 2010 e recebeu o nome de Política Gaúcha de Mudança sobre o Clima (PGMC, Lei 13.594/10).

A PNMC, bem como as leis estaduais sobre mudanças climáticas, se inserem em um novo modelo de legislações, consequência de uma (nova) característica das leis, a principiológica, de acordo com a opinião de José Guilherme Purvin de Figueiredo (BENJAMIN; FIGUEIREDO, 2011, p. 240) e que, hoje, tornou-se um novo modelo no ordenamento jurídico nacional.

A aprovação de uma legislação que abarcasse as mudanças climáticas seguiu a trilha de outros países e colocou o Brasil entre aqueles com leis mais avançadas em torno das questões climáticas. Na Europa, por exemplo, alguns dos países nórdicos e a Suíça, acrescidos da Alemanha e Reino Unido têm leis específicas sobre alterações do clima, conforme relata Anthony Giddens:

Tomando um vasto conjunto de indicadores de critérios ambientais, todos os países de melhor desempenho são democráticos. Segundo a classificação do Índice de Desempenho Ambiental elaborados pelas universidades de Yale e Columbia, os cinco melhores países do mundo são Suécia, Noruega, Finlândia, Suíça e, curiosamente, uma sociedade em desenvolvimento, a Costa Rica (GIDDENS, 2010, p. 101). 
Nos Estados Unidos, o estado da Califórnia tem um avançado programa de combate e prevenção às mudanças climáticas, inclusive tornando obrigatória uma disciplina escolar, desde o nível fundamental, sobre o tema, o que é sobremaneira inovador. Talvez em razão da iminência de uma catástrofe natural - terremoto advindo da falha geológica de San Andreas, as autoridades californianas tenham a noção de que a prevenção é uma das respostas mais adequadas em caso de desastres naturais.

Com a promulgação da PNMC em fins de 2009, o Brasil saiu na frente de outros países vizinhos como a Bolívia e o Peru, ambos com previsões muito pessimistas do IPCC e outros órgãos climáticos internacionais, pois com o (provável) degelo gradual da cordilheira dos Andes, ambos poderão sofrer enchentes catastróficas; ao mesmo tempo secas mais severas poderão tornar o pampa argentino árido.

\subsection{Política Nacional sobre Mudança Climática (Lei 12.187/09)}

A Política Nacional sobre Mudança do Clima (Lei 12.187/09) caracteriza-se por ser uma lei que estabelece princípios, objetivos, diretrizes e instrumentos, semelhante à Lei 6.938/81 - Política Nacional do Meio Ambiente - porém com um enfoque voltado para os problemas ambientais de segunda geração, vez que o seu conteúdo é afeto à sociedade de risco (LEITE; AYALA, 2002, p. 27). Já de início, em seu art. $2^{\circ}$, conceitua diversos termos relacionados às mudanças climáticas - tais como gases de efeito estufa e sumidouro - os quais ainda estão distantes do vocabulário dos destinatários da norma. Por isso há uma espécie de "glossário" dos termos técnico-ambientais.

No art. 3ำ estabelece a responsabilidade conjunta dos entes políticos e órgãos da administração pública pela execução do delimitado no PNMC e a observância de princípios como o da precaução e do desenvolvimento sustentável, além da participação cidadã. Por sua vez, o art. $5^{\circ}$ elenca uma série de diretrizes, tais como: [...] III - as medidas de adaptação para reduzir os efeitos adversos da mudança do clima e a vulnerabilidade dos sistemas ambiental, social e econômico; IV - as 
estratégias integradas de mitigação e adaptação à mudança do clima nos âmbitos local, regional e nacional.

\subsection{Política Estadual (Gaúcha) sobre Mudança do Clima (Lei 13.594/10)}

A Política Gaúcha sobre Mudança do Clima segue os moldes da Lei 12.187/09, arrolando em seu art. $6^{\circ}$ os seguintes princípios: I - a proteção do sistema climático para as gerações presentes e futuras; II - a prevenção; III - a precaução; IV - a participação e a cooperação pública; V - a garantia do direito à informação; VI - a educação ambiental; VII - o desenvolvimento sustentável; VIII as responsabilidades comuns; IX- o poluidor pagador; $\mathrm{X}$ - a transversalidade das ações do governo.

Já as diretrizes são previstas no art. $7^{0}$ e entre elas devem ser citadas as seguintes: I - adotar ações de educação ambiental e a conscientização social acerca das mudanças climáticas; II - formular, implementar, publicar e atualizar regularmente programas regionais que incluam medidas para mitigar a mudança do clima, enfrentar as mudanças antrópicas por fontes e remoções por sumidouros de todos os gases de efeito estufa não controlados pelo Protocolo de Montreal em todos os setores pertinentes, inclusive nos setores de energia, transportes, indústria, agropecuária, silvicultura e administração de resíduos.

Em uma análise conjunta das duas leis, verifica-se que ambas consagram a participação popular como princípio, mesmo que os termos não sejam os mesmos; na lei federal, a expressão utilizada é participação cidadã, enquanto na lei estadual, é participação pública. Portanto, o intuito do legislador era o de reconhecer que o público, a coletividade tem, aqui, um direito fundamental.

Em tempos de crise ambiental, em que as mudanças climáticas são consideradas um dos maiores desafios à humanidade, os dois planos de combate e prevenção às alterações do clima em estudo - Lei federal no 12.187/09 e Lei estadual (do Rio Grande do Sul) nº 13.594/10 - tratam da participação popular no rol dos princípios, o que significa dizer que a opção do legislador vai ao encontro do que documentos internacionais já haviam expresso - v.g., Declaração do Rio de 1992 
em seu art. 10.

Contudo, embora albergada pela lei federal e estadual, a participação popular continua ínfima em se tratando de questões ambientais. No que tange particularmente às mudanças climáticas e suas consequências desastrosas, a pouca participação parece ser fruto do não reconhecimento da gravidade do problema pela população em geral, como se o mesmo estivesse distante do nosso dia a dia.

Não se trata mais de alterações climáticas e seus efeitos nefastos em um futuro remoto, mas de graves alterações em andamento: o regime de chuvas em algumas regiões do Brasil já foi modificado e entre seus efeitos as enchentes e inundações são exemplos enquanto há secas mais severas em outras regiões.

Logo, o debate público sobre os novos cenários climáticos e como as repercussões daqueles afetarão a vida dos habitantes do Planeta Terra é imprescindível que se realize. As consequências nefastas das mudanças climáticas transcendem inclusive às outras questões ambientais. Não obstante se concorde com o sociólogo britânico Anthony Giddens acerca do paradoxo que existe na sociedade contemporânea, é mister, então, que os setores da sociedade que têm acesso ao conhecimento e ao saber sejam os indutores de um debate público sobre a necessidade da mitigação e/ou adaptação à nova realidade climática; além disso, as decisões políticas ou jurídicas no campo ambiental se legitimam adequadamente quando há uma efetiva participação popular.

Defende-se, neste espaço, um novo olhar, sob o viés jurídico-processual, que leva em consideração a necessidade do cidadão participar ativamente nas decisões que envolvam o meio ambiente, o que vai ao encontro de uma democracia participativa. Por isso, a adoção de uma audiência judicial participativa pode se constituir em uma tentativa de estabelecer uma decisão mais equânime e justa tratando-se de casos envolvendo o ambiente e as alterações climáticas.

Em razão do direito ao meio ambiente equilibrado ser um direito difuso, a participação ampla da população conferiria maior força à decisão judicial. Se em sede de julgamento de ADIs existe a possibilidade de audiência pública para a oitiva da sociedade e seus mais distintos setores, por que não se realizar o mesmo tipo de audiência em questões climático-ambientais? Assim, a audiência judicial 
participativa se insere na tendência contemporânea da cooperação no processo judicial e em um Estado Ambiental também de cooperação.

\section{A PARTICIPAÇÃO POPULAR NAS QUESTÕES AMBIENTAIS (CLIMÁTICAS)}

A participação popular significa envolvimento do cidadão; o processo decisório acerca de qualquer aspecto socioambiental adquire maior transparência e legitimidade com a presença do cidadão, nesse sentido diz José Rubens Morato Leite:

A participação redunda na transparência do processo e na legitimidade da decisão ambiental, contribuindo de maneira profunda para conscientização da problemática ambiental. E mais, esta transparência implicará uma decisão ambiental com maior consenso, com vistas à aceitação da coletividade e para a produção de seus efeitos de forma mais pacífica. Com efeito, através da participação, o que se discute é efetivamente uma via de mão dupla: Administração e Sociedade Civil, considerando que o meio ambiente não é propriedade do poder público e exige uma máxima discussão pública e a garantia de amplos direitos aos interessados. O apoio de todas as forças sociais nas decisões ambientais resultará em uma Administração mais aberta e menos dirigista (LEITE, 2003, p.37)

A percepção da sociedade civil de que as questões relacionadas ao meio ambiente não devem fazer parte somente da agenda das ONGs ambientalistas, do Ministério Público ou de órgãos governamentais federais, estaduais e municipais vem crescendo; entretanto, ainda há um déficit participativo que se vislumbra, por exemplo, em tema que envolve o modelo energético que o país deve seguir, tanto que, se não fosse o vazamento nuclear em Fukushima (março de 2011), o projeto de construção de uma nova usina nuclear estaria a pleno vapor, pois o programa nuclear brasileiro assim o previa (prevê).

\subsection{Modos de participação popular}

O estabelecimento de modos da participação popular se efetivar é estudado por Milaré, em percuciente análise de ideia defendida por Álvaro Mirra: 1) 
participação comunitária nos processos de criação do Direito do Ambiente; 2) participação popular através do Poder Judiciário; 3) participação popular na formulação e execução de políticas ambientais (MILARÉ, 2009, pp.195-196). O primeiro modo se subdivide em participação em órgãos colegiados dotados de poderes normativos (1.1); participação no processo legislativo (1.2). No que se refere à primeira subdivisão, é a participação em órgãos como o SISNAMA e o CONAMA; Conselhos Estaduais e Municipais do Meio Ambiente. Esses órgãos fazem parte de um arcabouço legislativo em que o Estado, em conjunto com os representantes da sociedade civil, regulamenta os mais variados aspectos referentes ao ambiente, desde a definição das zonas de amortecimento (entorno protetivo) das unidades de conservação, passando pelo licenciamento ambiental até o descarte de pilhas e baterias.

Referente às mudanças climáticas, já havia a Resolução 267/2000, dispondo sobre a proibição da utilização de substâncias que destroem a Camada de Ozônio em observância ao Protocolo de Montreal e as Resoluções 297 e 315/2002 e 342/2003, estabelecido limites para emissões de gases poluentes advindos de ciclomotores, motociclos e veículos automotores.

Já no que tange à segunda subdivisão, a participação ocorre ainda em fase preliminar, é dizer, quando o processo legislativo está em sua primeira fase e sofre os influxos da pressão popular, seja através das sugestões advindas dos setores interessados como do que hoje vem sendo feito - a consulta pública via internet; aliás a internet é um meio que pode aproximar o legislador da população.

O segundo modo aludido por Milaré é o que diz respeito à participação popular através do Poder Judiciário, utilizando-se instrumentos jurídico-processuais como a ação popular e a ação civil pública (MILARÉ, 2008, p.198). A utilização de tais instrumentos tem contribuído para a judicialização dos conflitos socioambientais, advindo daí o denominado "Judiciário ambientalista". Quanto ao conteúdo das decisões, não foi objeto do trablaho analisá-las, mas o fato é que o acesso à Justiça vem se perfectibilizando, embora também a produção da sentença/acórdão, por vezes, seja realizada sem a preocupação com a coerência e integridade e uma visão prospectiva sobre danos. 
O terceiro modo, por sua vez, ocorre através da formulação e execução de políticas públicas, é dizer, o cidadão deve participar na discussão, formulação e execução de tais políticas. Na opinião de Phillipi Jr.,

O exercício da cidadania inclui saber, atuar, buscar e cobrar alternativas para que as atividades antrópicas gerem menos impactos, como na ampliação de serviços de saneamento, na oferta de produtos ambientalmente corretos, de transporte coletivo eficiente, de energia limpa, entre outros (PHILLIPI JR., 2005, pp.7980).

Esse terceiro modo de participação popular citado (ainda) está longe de ser implementado no que se refere aos planos sobre mudanças climáticas, tanto em nível federal como estadual. A consagração de um princípio da participação cidadã revela que o Estado não pode (nem deve) assumir sozinho o ônus do combate e prevenção às alterações climáticas. Ele ainda é o ator mais importante, na medida em que induz e assegura a construção de um novo modelo socioambiental, mas a participação efetiva da população nas decisões ambientais é indispensável; não é possível mais se aceitar que a população permaneça alheia ao debate e escolhas sobre as mais variadas questões ambientais, desde a biotecnologia e as nanotecnologias até um (novo) modelo energético para o país.

\section{O PRINCÍPIO DA PARTICIPAÇÃO CIDADÃ (POPULAR) NAS POLÍTICAS NACIONAL E ESTADUAL SOBRE MUDANÇA DO CLIMA}

O princípio da participação cidadã expresso no art. $3^{\circ}$ da Lei federal sobre as Mudanças Climáticas tem feição semelhante a do princípio da participação popular insculpido na Lei 9.985/2000 (Lei do SNUC) e demais leis ambientais. No âmbito da Lei estadual ele está expresso no art. 6º IV, colocando ao lado da participação, a cooperação pública.

Há doutrina afirmando que o princípio da participação popular não deve ser dissociado dos princípios da informação e da educação (FARIAS, 2008, p.32), pois os três princípios devem andar lado a lado; somente um cidadão bem-informado (e, por óbvio, educado "ambientalmente") terá maior possibilidade de participar 
efetivamente de processos decisórios em âmbito administrativo ou expressando sua opinião em âmbito judicial.

A matriz constitucional do princípio da participação cidadã, assim como os demais insculpidos no art. $3^{\circ}$ da PNMC e no art. 6ำ, IV da PGMC, se infere do disposto no art. 225, caput da Constituição Federal, vez que ao determinar que todostêm o dever de defender e preservar o meio ambiente ecologicamente equilibrado para as presentes e futuras gerações, a Lei Maior fez também uma escolha pela participação social na gestão ambiental e impôs uma obrigação constitucional a toda a coletividade.

De acordo com Paulo Affonso Leme Machado, há três vertentes da participação na legislação ambiental: 1) participação das pessoas, através de ONGs, nos conselhos ambientais; 2) participação em ações judiciais; 3) participação das pessoas e entidades na fase de comentários e na fase de audiência pública no procedimento de estudo de impacto ambiental (MACHADO, 2008, p. 47).

Além da previsão legal de audiências públicas (v.g., art. 40 do Estatuto da Cidade) e da criação de unidade de conservação (art. $5^{\circ}$, III e $22, \S 2^{\circ}$ da Lei do SNUC), a participação é um imperativo na elaboração de políticas públicas ambientais, como é o caso da gestão urbano-ambiental das cidades, cuja lei Estatuto da Cidade - em seus artigos 43 e 44 prevê instrumentos para tal gestão.

Contudo, o que se verifica é que a participação pública é muito pequena em relação ao número de habitantes do Brasil e à magnitude dos problemas ambientais de segunda geração como é o caso das mudanças climáticas. Na ausência de uma democracia participativa em nosso país, instrumentos como o referendo ou o plebiscito, além da iniciativa popular de lei, constituem-se em um caminho mais democrático na elaboração e discussão de políticas públicas ambientais. Se as questões ligadas às mudanças climáticas em sede internacional têm cada vez mais recebido a atenção da população, o que se traduz em uma participação ativa, por que, em nosso país, o mesmo não poderia acontecer?

\subsection{Da audiência judicial participativa em casos envolvendo problemas ambientais de segunda geração}


O princípio da participação cidadã não foi eleito aleatoriamente pelo legislador a constar na PNMC; ao revés, significa que, embora estejamos em uma democracia representativa, mecanismos com características da democracia participativa são fundamentais quando se tratam de direitos difusos, transindividuais. Logo, a interpretação e aplicação de tal princípio passa por uma nova perspectiva do que seja participação cidadã (ativa) nos processos decisórios. Assim, assegurar e facilitar a participação direta do cidadão em processos envolvendo questões ambientais, em especial os referentes à situações que agravem a degradação ambiental e o aumento de emissões dos GEEs (e, portanto, agravam o cenário das mudanças climáticas), através de uma audiência judicial participativa, é estabelecer uma real democratização no processo judicial ambiental.

Conforme se depreende da opinião de Bodnar,

A participação efetiva dos destinatários das normas ambientais é a melhor estratégia a ser utilizada para o tratamento das lides ambientais mais complexas, tendo em vista que concretiza também os princípios da: informação, educação, conscientização e comprometimento solidário com proteção do meio ambiente;

Para tanto, faz-se imperioso inaugurar uma nova concepção de teoria do processo, voltada para o caráter difuso do Direito Ambiental que, fundamentalmente promova a garantia do processo como procedimento em contraditório; um processo de inclusão dos indivíduos em um ambiente dialético, no qual se reconhece o mérito de tratar cada sujeito do direito como igual e idêntico;

A melhor forma de assegurar o princípio da participação no processo judicial é a realização deaudiências judiciais participativas, nas quais deve ser oportunizada a participação direta dos cidadãos, de especialistas na matéria e das autoridades públicas, tudo para a construção conjunta de decisão social e ambientalmente mais justa e consequente (BODNAR, 2010, p.791).

Portanto, semelhante às audiências públicas em processo constitucional (ADls e outras ações constitucionais - $\S 1^{\circ}$ do art. 3ํ da Lei 9868/99) junto ao STF, a audiência judicial participativa em matéria ambiental que envolva problemas de segunda geração poderia contar com a participação direta da sociedade, o que pode ser vislumbrado através da oitiva (opinião) de ONGs conhecedoras do tema, por exemplo; bem como de associações de moradores, sindicatos, de experts que 
tenham relação com o tema do caso em concreto. Não há de se confundir a audiência judicial participativa com a audiência pública prevista administrativamente; esta é anterior àquela e deverá ocorrer toda vez que, por exemplo, um empreendimento necessitar de EIA-RIMA. Na judicial participativa, assim nos parece, há de certa forma, o compartilhamento de uma escolha (se "a" ou "b", ouvidos todos os segmentos e analisadas as posições de cada um). Nada mais é do que possibilitar uma gestão mais democrática de problemas ambientais que chegaram ao Judiciário.

Sendo assim, face à nova realidade climática, decorrente do aquecimento global, cujos conflitos poderão desaguar no Judiciário, a defesa de um instrumento que renova a dogmática processual tradicional e reconhece a importância da opinião da população, permitindo o acesso à Justiça ambiental, certamente auxilia na construção de uma cidadania ambiental plena. Esse é um dos méritos das leis trazidas a lume neste artigo, pois a participação cidadã nada mais é do que um direito fundamental reconhecido expressamente, podendo ser concretizado através da audiência judicial participativa.

Essa estratégia jurídico-ambiental é muito mais uma sugestão no plano processual, judicializadas as questões, do que propriamente a constatação e verificação do que já vem sendo realizado em nível de sociedade. Assim, o próximo item é o que trata da consulta pública realizada pelo Ministério do Meio Ambiente, outra estratégia jurídico-ambiental.

\section{A PARTICIPAÇÃO POPULAR, ATRAVÉS DA CONSULTA PÚBLICA, NA CONSTRUÇÃO DO PLANO NACIONAL DE ADAPTAÇÃO À MUDANÇA CLIMÁTICA: BREVE ANÁLISE CRÍTICA}

Em consonância com o que a Política Nacional sobre Mudança Climática e a doutrina ambiental prescrevem, o governo federal lançou no ano passado uma consulta pública sobre o Plano Nacional de Adaptação à Mudança do Clima (PNA) em que a população em geral deveria manifestar-se sobre esta estratégia jurídicoambiental de adaptação aos efeitos do câmbio climático. 
Segundo consta no site do Ministério do Meio Ambiente (MMA),

O Plano Nacional de Adaptação à Mudança do Clima (PNA) é um instrumento elaborado pelo governo federal em colaboração com a sociedade civil, setor privado e governos estaduais que tem como objetivo promover a redução da vulnerabilidade nacional à mudança do clima e à gestão do risco associado a esse fenômeno. O processo de construção do PNA está inserido no âmbito da governança que trata da mudança do clima no Brasil e envolve a participação de diversos ministérios, além do Fórum Brasileiro de Mudanças Climáticas (MMA, 2016).

$\mathrm{Na}$ elaboração desse Plano foram considerados 11 setores ou temas, representados pelos órgãos governamentais competentes que atuaram em conjunto por meio de um grupo de trabalho (GT Adaptação). Os setores abordados foram agricultura, recursos hídricos, segurança alimentar e nutricional, biodiversidade, cidades, gestão de risco aos desastres, indústria e mineração, infraestrutura, povos e populações vulneráveis, saúde e zonas costeiras. E cada um deles apresentou alguma contribuição ao Plano, identificando os impactos atuais e futuros com base em projeções do clima; analisando a vulnerabilidade a esses possíveis impactos e definindo as medidas adaptativas e diretrizes para determinado sistema.

Com o Plano Nacional de Adaptação às Mudanças Climáticas, cuja minuta foi submetida à consulta pública, o governo federal fez um mapeamento da vulnerabilidade de vários locais do país à incidência das mudanças climáticas, para ao final, em conjunto com outros atores sociais estabelecer prioridades e estratégias. Na consulta pública realizada, foi colocado à disposição do participante um formulário eletrônico que deveria ser respondido e enviado ao Ministério do Meio Ambiente.

Nesse formulário deveriam ser colocadas as contribuições e sugestões referentes aos itens que o participante entendesse ser modificado ou melhorado. $O$ período de realização da consulta foi relativamente curto (3 meses), tendo sido prorrogado até 22 de novembro de 2015 e os resultados quanto à origem da região dos participantes depreende-se da figura abaixo. 
Conforme relatório do Grupo de Trabalho sobre Adaptação, no período de vigência da consulta, foram recebidos 134 formulários válidos, vide a seguir a origem dos participantes

Figura 1. Distribuição regional dos respondentes

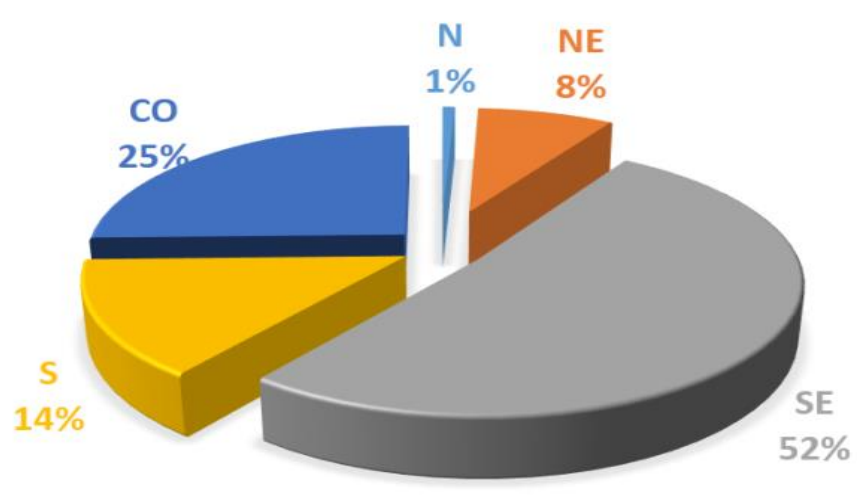

(Fonte: Ministério do Meio Ambiente, PNA, março de 2016)

Houve a participação de respondentes de todas as regiões brasileiras, mas os maiores percentuais de registro foram os das regiões Sudeste e Centro- Oeste, com $52 \%$ e $25 \%$, respectivamente.

Quanto à distribuição dos respondentes por Unidade da Federação (UF), São Paulo, Distrito Federal e Rio de Janeiro foram as que apresentaram maior número de participações dentre as 16 UF registradas, com 26, 24 e 18\%, respectivamente (Figura 2 ) 
Figura 2. Percentual de formulários válidos recebidos por UF

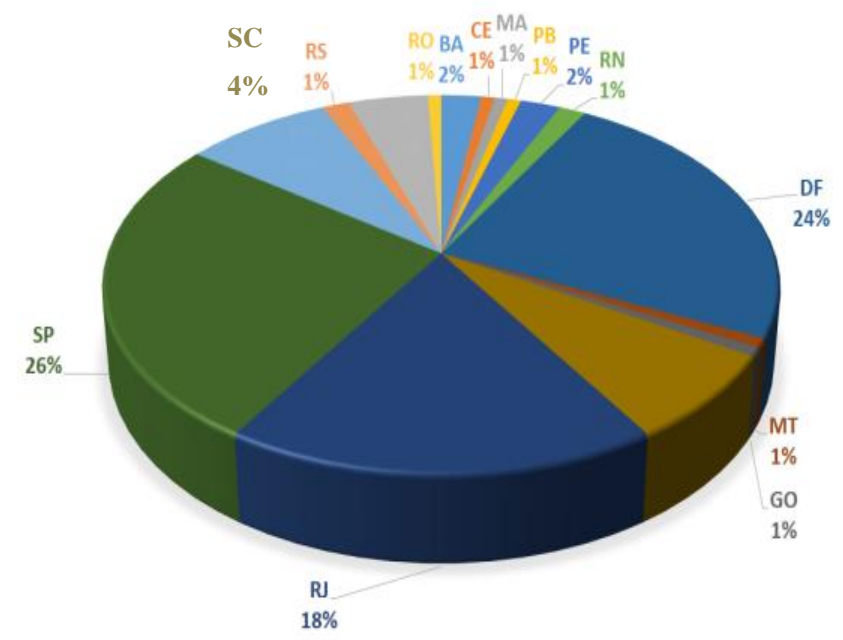

. (Fonte: Ministério do Meio Ambiente).

Quanto ao tipo de opinião expressa nas contribuições, 58\% correspondem à visão pessoal do respondente e $48 \%$ a uma visão institucional (setor empresarial, governamental, academia e sociedade civil organizada).

Esses números e percentuais foram divulgados no site do próprio Ministério do Meio Ambiente e denotam que houve baixíssima participação popular nessa consulta pública. Tão-somente 134 formulários eletrônicos foram aceitos para integrar a referida consulta. É um número insuficiente para estabelecer uma efetiva participação popular na confecção de um plano tão importante como é o PNA. Não obstante tenha sido aberto à população em geral, o maior número de formulários eletrônicos foi respondido por instituições de atuação na seara climático-ambiental. Em um universo de mais de 200 milhões de habitantes no Brasil, esse número de 134 definitivamente não é representativo do que deseja ou sugere a população.

Se o Ministério do Meio Ambiente tem todos os canais e instrumentos para publicizar uma consulta pública, por que estabelecer um prazo tão curto para eventuais contribuições e sugestões? E mais, qual o critério utilizado - não ficou claro na divulgação dos dados - para escolher aqueles 134 formulários? Acaso, nessa escolha, teve preferência o formulário que nada sugeriu ou que nada contestou sobre a minuta? 
Em documento produzido na 28a Reunião do Grupo de Trabalho sobre Adaptação, as considerações acerca da consulta pública são mínimas, in verbis:

\subsection{Divulgação do relatório da consulta pública}

Inicia-se então a discussão à respeito dos encaminhamentos para a relatoria da Consulta pública e resposta à sociedade. O representante do MMA explica que ao se observar o princípio de transparência, seria adequado compilar as contribuições recebidas para anexar ao relatório da Consulta pública.

Consensos alcançados:

- Preparar (circular previamente no GT) e disponibilizar à sociedade um relatório estatístico da consulta pública, contendo como anexo todas as contribuições recebidas, mas sem a identificação da pessoa que contribuiu;

- Encaminhar carta de agradecimento às pessoas que contribuíram.

Os resultados divulgados por um dos formuladores e executores da política pública de prevenção e combate às mudanças climáticas denotam, ainda que em primeiras impressões, a ideia que mesmo com o acesso on line à consulta pública, não há um comparecimento expressivo da população. Vale registrar que o Ministério do Meio Ambiente também não utilizou em qualquer etapa do processo de consulta mais de um canal de divulgação que pudesse ampliar o acesso da população à consulta. O que se verifica é que, embora a consulta pública seja um instrumento de democracia participativa nas questões climático-ambientais, ainda está longe de poder ser considerada como o espelho do que realmente deseja a população.

\section{CONSIDERAÇÕES FINAIS}

O aquecimento global e as mudanças climáticas fazem parte da agenda internacional como um tema transversal afeto a todas as áreas do conhecimento. Não sem razão a mais nova preocupação da comunidade científica internacional com a recente declaração do presidente norte-americano, Donald Trump, de que os Estados Unidos se retirarão do Acordo de Paris (Folha de São Paulo, 2017), assinado na gestão Barack Obama, o que se constitui em evidente retrocesso às negociações internacionais sobre os níveis de emissão dos GEEs de cada país e à 
política global de prevenção e mitigação às mudanças climáticas. Isso se constitui em fato que vai de encontro ao arcabouço jurídico internacional criado em torno do tema e, de alguma forma, prejudicará o normal desenvolvimento da política internacional.

No que tange ao tema em análise - a participação popular na construção de um regime jurídico que abarque as mudanças climáticas - a posição do governo norte-americano é respaldada justamente por parte da população que, além de cética quanto ao aquecimento global e a incidência das mudanças climáticas, crê que a mera posição (isolada) de grande potência poderá lhes proteger dos efeitos nefastos das mudanças climáticas. Um posicionamento que denota a ausência de um maior debate na sociedade norte-americana sobre o tema.

Situação não muito distinta, infelizmente, da sociedade brasileira. Em pesquisa realizada entre 11 a 13 de março de 2015, o Greenpeace, o Observatório do Clima e o Datafolha realizaram entrevistas com 2100 brasileiros, em todas as regiões, que opinaram sobre as mudanças climáticas. Divulgado com o título Mudanças Climáticas. O que pensa o brasileiro, a pesquisa, entre outros resultados, atestou que $88 \%$ dos entrevistados tinham uma grande preocupação com o tema; e que para $84 \%$, o governo federal estava fazendo menos do que deveria fazer ou não fazia nada quanto às mudanças climáticas. Esses resultados retratam o que foi verificado ao longo desse ensaio, qual seja, conhece-se a urgência do tema, há preocupação com o mesmo, contudo, muito pouco tem se realizado para que as mudanças climáticas e a política pública que dela trata se firme como tema premente na sociedade brasileira.

Discutiu-se o processo de produção de um fato científico - as mudanças climáticas - e suas implicações na sociedade. Tendo como objetivo geral a análise desse fato científico e objetivo específico a política pública em que foram expressas as diretrizes e princípios referentes ao câmbio climático, estudou-se o princípio da participação cidadã (popular) como um dos fundamentos da Política Nacional sobre Mudança do Clima (Lei 12.187/2009).

No estabelecimento de estratégias jurídico-ambientais de combate, prevenção e adaptação às mudanças climáticas, tal política pública é um dos instrumentos que 
- Estado brasileiro tem à sua disposição para internalizar o decidido em fóruns internacionais como é o caso do Protocolo de Quioto ou o mais recente acordo internacional, o Acordo de Paris.

Não obstante a PNMC busque uma atuação conjunta entre o Estado, as empresas e a sociedade civil na formulação e consecução de planos de mitigação e/ou adaptação às mudanças climáticas, há indicativos ao longo do artigo que a participação popular ainda é insuficiente ou ínfima, seja no âmbito do processo judicial ambiental (= ausência de uma audiência judicial participativa) ou mesmo no âmbito da produção de um plano específico que trata da adaptação - de todos os setores e da população em geral - ao câmbio climático, já que na consulta pública realizada pelo Ministério do Meio Ambiente houve somente 134 participantes, mesmo tendo sido publicizada anplamente a consulta e o objetivo da mesma.

Nesse espaço acadêmico, a consideração crítica é no sentido de que, no mínimo, esta consulta pública não atende ao real sentido da participação popular, embora não se tenha realizado entrevistas com os atores envolvidos e feita tão-só a análise dos números e gráficos, divulgados pelo Ministério do Meio Ambiente, tendo o público participante enviado os formulários eletrônicos com as suas respostas e sugestões.

Quando se analisam dados como os antes referidos e mesmo as pesquisas de organizações atuantes na área ambiental como o Greenpeace, emerge uma conclusão nada satisfatória, qual seja: a percepção do brasileiro sobre as mudanças climáticas é - ainda - a de quem ignora o risco que o câmbio climático traz à saúde, ao trabalho, ao transporte, etc. Infelizmente, não é mais possível deter as mudanças climáticas (e as ondas de calor letal têm demonstrado isso) ${ }^{3}$, mas adaptar-se às mesmas ou mitiga-las não está no horizonte da maioria dos brasileiros. Continua

\footnotetext{
${ }^{3} \mathrm{O}$ jornal eletrônico, reconhecido pela comunidade científica internacional, Nature Climate Change divulgou relatório produzido por cientistas de vários países de que um terço da população mundial já enfrenta hoje ondas de calor letais. A pesquisa analisou mais de 1,9 mil casos de fatalidades associadas a ondas de calor em 36 países nos últimos 40 anos e concluiu que o risco global de doenças relacionadas com o calor aumentou de forma constante desde 1980. In: MORA, Camilo; DOUSSET, Bénedicte et all. Global risk of deadly heat. Nature Climate Change, jun. 2017. Disponível em: http:///www.nature.com/nclimate/journal/vaop/ncurrent/ful/nclimate3322.html . Acesso em 21.jun.2017 .
} 
sendo, portanto, mais um dos desafios do nosso tempo a inserção do tema participação popular nos debates em torno do aquecimento global e as mudanças climáticas.

\section{REFERÊNCIAS}

BENJAMIN, Antonio Herman e FIGUEIREDO, José Guilherme Purvin de (coord.). Direito ambiental e as funções essenciais à justiça: o papel da advocacia de estado e da defensoria pública na proteção do meio ambiente. São Paulo: Revista dos Tribunais, 2011.

BRASIL. Lei 12.187, de dezembro de 2009. Disponível em http://www.senado.gov.br . Acesso em 20. jan.2016.

MINISTÉRIO DO MEIO AMBIENTE. Plano Nacional de Adaptação à Mudança Climática (PNA). Brasília: Ministério do Meio Ambiente, v. 1. Disponível em http//www.mma.gov.br. Acesso em 1ํ. abr. 2016.

BECK, Ulrich. Ecological Politics in an Age of Risk. Cambridge: Polity Press, 1995.

. La sociedad del riesgo global. Madrid: Siglo XXI de España, 2002.

. GIDDENS, Anthony; LASH, Scott. Modernização Reflexiva: política, tradição e estética na ordem social moderna. São Paulo: UNESP, 1997.

BODNAR, Zenildo. Audiência Judicial Participativa como instrumento de acesso à Justiça Ambiental: diálogo com Elio Fazzalari. In Anais da VII Jornada LusoBrasileira de Direito do Ambiente, Florianópolis, nov. 2010.

CANOTILHO, José Joaquim Gomes. Introdução ao direito do ambiente. Lisboa: Universidade Aberta, 1998.

e LEITE, José Rubens Morato (organizadores). Direito constitucional ambiental brasileiro. 3. ${ }^{a}$ ed. São Paulo: Saraiva, 2010.

FARIAS, Talden. O princípio da participação popular no Direito Ambiental brasileiro e a sua contribuição para a proteção do meio ambiente. Revista Fórum de Direito Urbano e Ambiental, n. 37, jan./fev. 2008, p. 32.

FOLHA DE SÃO PAULO. Trump anuncia retirada dos EUA do Acordo de Paris. Disponível em: www.folha.uol.com.br/.../1889367-trump-anuncia-retirada-dos-euado-acordo-de-paris. Acesso em 1‥jul.2017. 
GERRARD, Michael B. Global Climate Change. New York: Columbia University Press, 2008. University, 2012.

Sustainable Development Law and Policy. New York: Columbia GIDDENS, Anthony. A política da mudança climática. Tradução de Vera Ribeiro. Rio de Janeiro: Zahar, 2010.

A terceira via: Reflexões sobre o impasse político-atual e o futuro da social democracia. Tradução de Maria Luiza Borges. Rio de Janeiro: Record , 1999.

INPE. Riscos das mudanças climáticas no Brasil. Análise conjunta Brasil-Reino Unido sobre os impactos das mudanças climáticas e do desmatamento na Amazônia. José Marengo (Brasil) e Richard Betts (Reino Unido) - coordenadores. São Paulo, maio 2011.

IPCC, 2014: Cambio climático 2014: Informe de síntesis. Contribución de los Grupos de trabajo I, II e III al Informe de evaluación del Grupo Intergubernamental de Expertos sobre Cambio Climático. IPCC.

KOLBERT, Elizabeth. Field Notes From a Catastrophe: Man, Nature, and Climate Change. London-UK: Bloomsbury Publishing PLC, 2007.

LEITE, José Rubens Morato. Dano ambiental: do individual ao coletivo, extrapatrimonial. 2. ed. São Paulo: Revista dos Tribunais, 2003.

. Sociedade de risco e Estado. In: CANOTILHO, José J. Gomes e LEITE, José Rubens Morato. Direito constitucional ambiental brasileiro. 3.ed. São Paulo: Saraiva, 2010.

MACHADO, Paulo Affonso Leme. Direito ambiental brasileiro. 16. ed. São Paulo: Malheiros, 2008.

. Direito à informação e meio ambiente. São Paulo: Malheiros, 2006.

MILARÉ, Édis. Direito do ambiente: a gestão ambiental em foco: doutrina, jurisprudência, glossário. 6. ed., São Paulo: Revista dos Tribunais, 2009.

MORA, Camilo; DOUSSET, Bénedicte et all. Global risk of deadly heat. Nature Climate Change, jun. 2017.2 Disponível em: http:///www.nature.com/nclimate/journal/vaop/ncurrentlful/nclimate3322.html Acesso em 21.jun.2017 . 
PHILIPI JR., Arlindo e ALVES, Alaôr Caffé (editores). Curso interdisciplinar de direito ambiental. Barueri, SP: Manole, 2005.

SARLET, Ingo Wolfgang e FENSTERSEIFER, Tiago. Direito constitucional ambiental: (estudos sobre a constituição, os direitos fundamentais e a proteção do ambiente). São Paulo: Revista dos Tribunais, 2011.

(org.). Estado socioambiental e direitos fundamentais. Porto Alegre: Livraria do Advogado, 2010.

YOSHIDA, Consuelo Yatsuda Morimizato. Mudanças climáticas, Protocolo de Quioto e o princípio da responsabilidade comum, mas diferenciada. A posição estratégica do Brasil. O Direito por um Planeta Verde. Artigos. Disponível em http://www.planetaverde.org, acesso em 17. jan.2016. 